Article

\title{
Survival Outcomes Associated with First and Second-Line Palliative Systemic Therapies in Patients with Metastatic Bladder Cancer
}

\author{
Arshia Beigi ${ }^{1,+}$, Saba Vafaei-Nodeh ${ }^{2,+}$, Longlong Huang ${ }^{3}$, Shaun Z. Sun ${ }^{3}$ and Jenny J. Ko ${ }^{4, *}$ \\ 1 Department of Medicine, University of British Columbia, Vancouver, BC V6T 1Z3, Canada; \\ abeigi@student.ubc.ca \\ 2 Faculty of Medicine, University of British Columbia, Vancouver, BC V6T 1Z3, Canada; sabavk@student.ubc.ca \\ 3 Faculty of Mathetmatics and Statistics, University of the Fraser Valley, Abbotsford, BC V2S 7MH, Canada; \\ longlong.huang@ufv.ca (L.H.); shaun.sun@ufv.ca (S.Z.S.) \\ 4 Department of Medical Oncology, British Columbia Cancer, Abbotsford, BC V2S 0C2, Canada \\ * Correspondence: jenny.ko@bccancer.bc.ca \\ + Co-first authors.
}

check for

updates

Citation: Beigi, A.; Vafaei-Nodeh, S.; Huang, L.; Sun, S.Z.; Ko, J.J. Survival Outcomes Associated with First and Second-Line Palliative Systemic

Therapies in Patients with Metastatic Bladder Cancer. Curr. Oncol. 2021, 28, 3812-3824. https://doi.org/10.3390/ curroncol28050325

Received: 18 July 2021

Accepted: 23 September 2021

Published: 29 September 2021

Publisher's Note: MDPI stays neutral with regard to jurisdictional claims in published maps and institutional affiliations.

Copyright: (c) 2021 by the authors. Licensee MDPI, Basel, Switzerland. This article is an open access article distributed under the terms and conditions of the Creative Commons Attribution (CC BY) license (https:// creativecommons.org/licenses/by/ $4.0 /)$.
Abstract: Background: Real-world data on palliative systemic therapies (PST) in treating metastatic bladder cancer $(\mathrm{mBC})$ is limited. This study investigates current trends in treating $\mathrm{mBC}$ with first(1L) and second-line (2L) chemotherapy (CT) and immunotherapy (IT). Methods: A chart review was conducted on patients diagnosed with stage II-IV bladder cancer in 2014-2016. Survival outcomes were compared between chemotherapy, immunotherapy, and supportive care. Results: out of 297 patients, $77 \%$ were male. $44 \%$ had stage IV disease at diagnosis. Median age at metastasis was 73 years. $40 \%$ of patients received 1L PST and 34\% received 2L PST. Median overall survival (mOS) was longer in those receiving PST versus no treatment $(p<0.001)$. Patients receiving CT and IT sequentially had the longest mOS (18.99 months). First-line IT and CT mOS from treatment start dates were 5.03 and 9.13 months, respectively $(p=0.81)$. Gemcitabine with cisplatin ( 8.88 months) or carboplatin (9.13 months) were the most utilized $1 \mathrm{~L}$ chemotherapy regimens $(p=0.85)$. $2 \mathrm{~L}$ IT and CT mOS from treatment start dates were 6.72 and 3.78 months, respectively $(p=0.15)$. Conclusion: real-world mOS of $>1.5$ years in $\mathrm{mBC}$ is unprecedented and supports using multiple lines of PST. Furthermore, immunotherapy may be a comparable alternative to chemotherapy in both $1 \mathrm{~L}$ and 2L settings.

Keywords: metastatic bladder cancer; chemotherapy; immunotherapy; survival; real-world data

\section{Introduction}

Bladder cancer is the most common malignancy of the urinary system, and the ninth most common in the world [1]. In 2020, an estimated 81,400 newly diagnosed cases of bladder cancer and 17,980 associated deaths were expected in the US [2]. Approximately $5 \%$ of new cases of bladder cancer are metastatic at diagnosis, and half of the patients diagnosed with muscle-invasive disease develop metastasis within two years $[3,4]$. The overall 5-year survival for any stage bladder cancer is $76.9 \%$, however, metastatic disease carries a much worse prognosis with a 5-year survival rate of only 5.5\% [4].

Approximately $90 \%$ of bladder cancers diagnosed in developed countries are classified as urothelial carcinoma otherwise known as transitional cell carcinoma [5]. The recommended first-line regimen for the treatment of metastatic urothelial bladder cancer involves cisplatin-containing combination chemotherapy, such as gemcitabine and cisplatin or methotraxate, vinblastine, doxorubicin, and cisplatin (both level 1b evidence) [6]. However, up to $50 \%$ of patients with metastatic bladder cancer are ineligible for cisplatin-based treatments [7]. This can be due to either poor performance status (ECOG $\geq 2$ ), other comorbidities (including kidney disease, neuropathy, hearing difficulties, etc) or inability 
to tolerate the adverse effects of therapy [7]. Patients that are ineligible for cisplatinbased therapies may benefit from carboplatin in combination with gemcitabine instead (level 2a) [6].

With disease progression on chemotherapy, immunotherapy is often offered in the second-line setting. These FDA-approved immune-checkpoint inhibitors include antiprogrammed cell death-1 (PD-1) antibodies (e.g., pembrolizumab and nivolumab) and anti-programmed cell death ligand-1 (PD-L1) antibodies (e.g., atezolizumab, durvalumab and avelumab). Currently, pembrolizumab is the only immunotherapy agent with level $1 \mathrm{~b}$ evidence for use in second-line setting; however, alternative agents such as atezolizumab and nivolumab (level 2a) have also been used. Immunotherapy may be used in a firstline setting in either cisplatin-ineligible patients with high PD-L1 expression or those ineligible for any platinum-based therapies (level 2a) [6]. Recently, a phase III clinical trial has demonstrated a significant increase in overall survival using avelumab as maintenance therapy in individuals with metastasis who have completed platinum-based therapy and have achieved at least a stable disease [8].

Limited data exist to show the benefit of immunotherapy in real-world patients with locally advanced unresectable or metastatic bladder cancer who may otherwise not have been able to enroll in or qualify for clinical trials. Considering all of the recent advances in the treatment of metastatic bladder cancer $(\mathrm{mBC})$, we sought to understand the use and effectiveness of various palliative systemic therapies (PSTs) in the real-world setting. Therefore, the purpose of this study is to report on patterns of treatment provided to patients with $\mathrm{mBC}$ as well as to compare survival outcomes of immunotherapy and chemotherapy using a population-based database.

\section{Materials and Methods}

\subsection{Study Design and Patient Population}

Approval was obtained from the Research Ethics Board to conduct a retrospective chart review of all patients in the BC Cancer database diagnosed with stage II-IV bladder cancer between 1 January 2014 to 31 December 2016. Data was collected from the date of bladder cancer diagnosis until 1 July 2020, date of death, or the last date of follow-up, whichever occurred first. Patients with metastatic disease were then identified and information was collected on patient demographics, tumor histopathology (grade, histology, presence of lymphovascular invasion), disease characteristics, as well as initial and subsequent treatments provided. Patients were staged using the American Joint Committee on Cancer (AJCC) 8th Edition TNM system [9]. Stage IV disease was defined as metastatic disease to distant lymph nodes (IVA) and/or visceral organs (IVB). Staging was based on pathology reports from transurethral resection of bladder tumor (TURBT) or radical cystectomy procedures, as well as imaging reports including computed tomography, magnetic resonance imaging, nuclear medicine, and positron emission tomography. Survival outcomes were compared between treatment modalities from the date of metastasis. To further understand the efficacy of treatments, outcomes were also compared in first-line $(1 \mathrm{~L})$ and second-line $(2 \mathrm{~L})$ settings. Patients were excluded if they received $1 \mathrm{~L}$ or $2 \mathrm{~L}$ agents as part of a clinical trial. Furthermore, patients were excluded from $1 \mathrm{~L}$ analysis if they were diagnosed with metastasis in the last six months of data collection. Additionally, patients were excluded from $2 \mathrm{~L}$ analysis if $1 \mathrm{~L}$ therapy was terminated within the last six months of data collection.

\subsection{Clinical Outcomes}

In the overall analysis, patient survival outcomes were compared between those receiving immunotherapy (IT) only, chemotherapy (CT) only, both chemotherapy and immunotherapy and no treatment (NT). Overall survival (OS) was defined as the time from date of metastasis to the earliest of death or last follow-up.

In the $1 \mathrm{~L}$ analysis, median OS (mOS) was compared between IT or CT versus NT with OS defined as the time from date of metastasis to the earliest of death or last follow-up. Sub- 
sequently, we compared clinical outcomes within the cohorts of patients undergoing (a) 1L therapy, including IT versus $\mathrm{CT}$, and (b) $1 \mathrm{~L}$ platinum-based combination chemotherapy, including gemcitabine with cisplatin (GCis) or carboplatin (GCarb). The primary outcome here was OS, defined as the time from the initiation of therapy to the earliest of death or last follow-up.

Similarly, in the 2L setting, OS analysis was conducted for patients receiving treatment (IT or CT) versus NT. Here, OS was defined as the time from termination date of $1 \mathrm{~L}$ therapy to the earliest of death or last follow-up. Clinical outcomes were also directly compared in patients treated with 2L IT versus CT. The primary outcome was OS, defined as the time from the initiation of $2 \mathrm{~L}$ therapy to the earliest of death or last follow-up.

\subsection{Statistical Analysis}

Statistical analysis was performed using the R software (version 3.6.3). All of the reported $p$-values were two-sided and a value of $<0.05$ was considered statistically significant. The primary analysis used log-rank test to compare overall survival between groups. Overall survival curves were constructed using the Kaplan-Meier method. Treatment effects were estimated from Cox regression analyses when proportional hazards could be assumed. If this assumption, however, was violated, then the restricted mean survival time was used to estimate survival differences over a follow-up period of three or four years based on the minimum survival time.

\section{Results}

A total of 297 patients with $\mathrm{mBC}$ were included in this study. Table 1 summarizes baseline patient, disease, and treatment characteristics. The majority of the patient population was male $(77 \%)$. The median age at metastasis was 73 years. Most patients had a high-grade tumor $(92 \%)$. Histologies included urothelial $(78 \%)$, mixed $(15 \%)$, neuroendocrine $(4 \%)$, squamous $(2 \%)$ and glandular $(<1 \%)$. Cancer stage at initial presentation consisted of: II ( $25 \%)$, III ( $31 \%)$, and IV (44\%). In this patient cohort, $46 \%$ received radical cystectomy and $25 \%$ received curative chemotherapy prior to metastasis.

Table 1. Patient, disease, and treatment characteristics of the overall cohort.

\begin{tabular}{ccc}
\hline \multicolumn{2}{c}{ Variable } & Overall (N= 297) \\
\hline Gender (Male), number of patients & $228(77 \%)$ \\
\hline Age at metastasis in years, median (range) & High & $73(36-98)$ \\
\cline { 2 - 3 } Grade, number of pts (\%) & Intermediate & $272(92 \%)$ \\
\cline { 2 - 3 } & Low & $7(3 \%)$ \\
\cline { 2 - 3 } & Unknown & $5(2 \%)$ \\
\cline { 2 - 3 } Histology, number of pts (\%) & Urothelial & $13(4 \%)$ \\
\cline { 2 - 3 } & Squamous & $231(78 \%)$ \\
\cline { 2 - 3 } & Neuroendocrine & $5(2 \%)$ \\
\cline { 2 - 3 } & Glandular & $2(<1 \%)$ \\
\cline { 2 - 3 } & Undifferentiated/other & $14(15 \%)$ \\
\hline Lymphovascular invasion, number of pts (\%) & $108(36 \%)$ \\
\hline
\end{tabular}


Table 1. Cont.

\begin{tabular}{|c|c|c|}
\hline \multicolumn{2}{|c|}{ Variable } & \multirow{2}{*}{$\begin{array}{c}\text { Overall }(N=297) \\
75(25 \%)\end{array}$} \\
\hline \multirow{3}{*}{$\begin{array}{l}\text { Stage at initial diagnosis, number } \\
\text { of pts (\%) }\end{array}$} & II & \\
\hline & III & $91(31 \%)$ \\
\hline & IV & $130(44 \%)$ \\
\hline \multicolumn{2}{|c|}{ Radical cystectomy, number of pts (\%) } & $137(46 \%)$ \\
\hline \multicolumn{2}{|c|}{ Radical radiotherapy, number of pts (\%) } & $27(9 \%)$ \\
\hline \multicolumn{2}{|c|}{ Prior curative chemotherapy use, number of pts (\%) } & $73(25 \%)$ \\
\hline
\end{tabular}

Of note, each of the characteristics in Table 1 were compared between the three treatment groups (IT only, CT only and both CT and IT). There were no significant differences in terms of basic patient demographics or tumor histopathology among the groups. However, all of the patients in IT only group had recurrent metastatic disease, and they were more likely to have received prior definitive therapies.

Figure 1 summarizes the pattern of treatments in our patient cohort. Of the 297 patients with metastatic disease, $40.4 \%$ received 1L PSTs, including chemotherapy $(37.0 \%)$ and immunotherapy $(3.4 \%)$, whereas $59.6 \%$ received no systemic treatment. Of the 116 patients who received 2L therapy, $12.1 \%$ received chemotherapy, $21.6 \%$ immunotherapy and $66.4 \%$ did not receive any further systemic treatment. Table A1 summarizes the palliative therapies used as first- and second-line agents in this study.

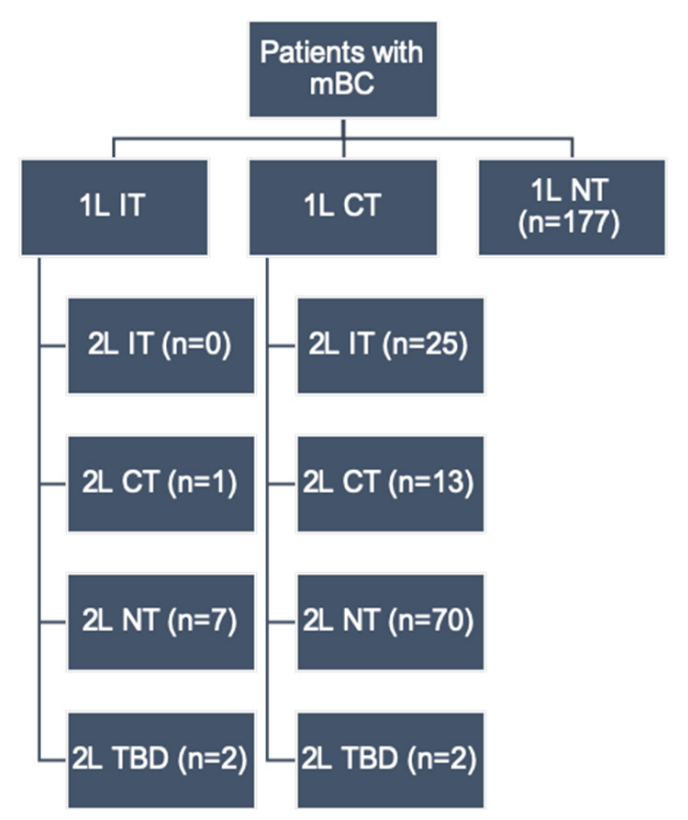

Figure 1. Palliative systemic therapy by line. Abbreviations: $\mathrm{mBC}=$ metastatic bladder cancer, $1 \mathrm{~L}=$ first-line, $2 \mathrm{~L}=$ second-line, $\mathrm{CT}=$ chemotherapy, $\mathrm{IT}=$ immunotherapy, $\mathrm{NT}=$ no treatment, $\mathrm{TBD}=$ to be decided (i.e. patient has not completed $1 \mathrm{~L}$ therapy or was being considered for $2 \mathrm{~L}$ therapy at the time of data collection).

Table 2 summarizes survival outcomes based on treatment modalities. Patients who did not receive any palliative systemic therapies had mOS of 3.16 months. Among the patients receiving treatment, those receiving both CT and IT had the longest survival with mOS of 18.99 months (HR: $0.231 ; p<0.0001$ ). In comparison, the CT only and IT only groups had mOS of 10.82 (HR: 0.362; $p<0.0001$ ) and 11.10 months (HR: 0.296; $p=0.004$ ), respectively (Figure 2 ). 
Table 2. Survival outcomes in patients receiving palliative therapies, calculated from date of metastasis.

\begin{tabular}{|c|c|c|c|c|}
\hline Overall Survival & $\begin{array}{c}\text { IT Only } \\
N=9\end{array}$ & $\begin{array}{l}\text { CT Only } \\
N=85\end{array}$ & $\begin{array}{l}\text { Both CT \& IT } \\
\quad N=26\end{array}$ & $\begin{array}{c}\mathrm{NT} \\
\text { (Reference) } \\
N=\mathbf{1 7 7}\end{array}$ \\
\hline $\begin{array}{c}\text { mOS } \\
\text { (95\% CI; months) }\end{array}$ & $\begin{array}{c}11.10 \\
(7.79-\mathrm{NA})\end{array}$ & $\begin{array}{c}10.82 \\
(9.26-13.59)\end{array}$ & $\begin{array}{c}18.99 \\
(16.23-30.26)\end{array}$ & $\begin{array}{c}3.16 \\
(2.69-3.66)\end{array}$ \\
\hline $\begin{array}{l}\text { Log-rank test } \\
p \text {-value }\end{array}$ & 0.004 & $<0.0001$ & $<0.0001$ & - \\
\hline $\begin{array}{c}\mathrm{HR} \\
(95 \% \mathrm{CI})\end{array}$ & $\begin{array}{c}0.296 \\
(0.13-0.67)\end{array}$ & $\begin{array}{c}0.362 \\
(0.27-0.48)\end{array}$ & $\begin{array}{c}0.231 \\
(0.15-0.37)\end{array}$ & - \\
\hline $\begin{array}{l}\text { Non-proportionality } \\
p \text {-value }\end{array}$ & 0.29 & 0.0002 & 0.0001 & - \\
\hline $\begin{array}{c}\text { RMST } \\
\text { (95\% CI; months) }\end{array}$ & $\begin{array}{c}18.61 \\
(6.31-30.91)\end{array}$ & $\begin{array}{c}15.07 \\
(12.27-17.87)\end{array}$ & $\begin{array}{c}23.68 \\
(18.73-28.63)\end{array}$ & $\begin{array}{c}5.46 \\
(4.33-6.59)\end{array}$ \\
\hline $\begin{array}{l}\text { RMST difference (95\% } \\
\text { CI; months) }\end{array}$ & $\begin{array}{c}13.15 \\
(0.80-25.50)\end{array}$ & $\begin{array}{c}9.60 \\
(6.58-12.62)\end{array}$ & $\begin{array}{c}18.22 \\
(13.14-23.29)\end{array}$ & - \\
\hline $\begin{array}{c}\text { RMST difference } \\
p \text {-value }\end{array}$ & 0.037 & $<0.0001$ & $<0.0001$ & - \\
\hline
\end{tabular}

IT: immunotherapy; CT: chemotherapy; NT: no treatment. mOS: median overall survival. HR: hazard ratio CI: confidence interval. RMST: restricted mean survival time; restricted at 48 months (4 years).

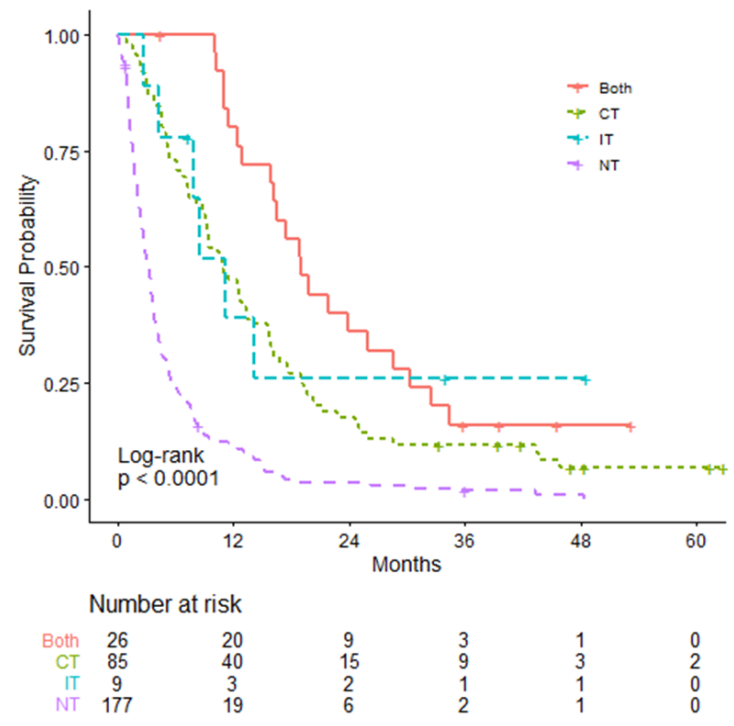

Figure 2. Overall survival in patients receiving palliative therapies, calculated from date of metastasis. Chemotherapy (CT), immunotherapy (IT), chemotherapy and immunotherapy (both) or no treatment $(\mathrm{NT})$.

The survival for 1L therapy, calculated from time of metastasis, is illustrated in Figure 3a. The mOS for the NT group was significantly shorter compared to either the IT or CT groups $(p<0.01$; Table A2). When calculated from the treatment start date, the mOS was 5.03 months for the 1L IT group and 9.13 months for the 1L CT group (HR: $0.911 ; p=0.81$; Table A3 and Figure 3b). For the 89 patients receiving $1 \mathrm{~L} \mathrm{CT,} 40.4 \%$ received GCis and $59.6 \%$ received GCarb (Table A4). There was no significant difference (Figure 4) in survival amongst the two groups (GCis mOS: 8.88 months, GCarb mOS: 9.13 months, HR: 1.044, $p=0.85)$ when calculated from the treatment start date. 

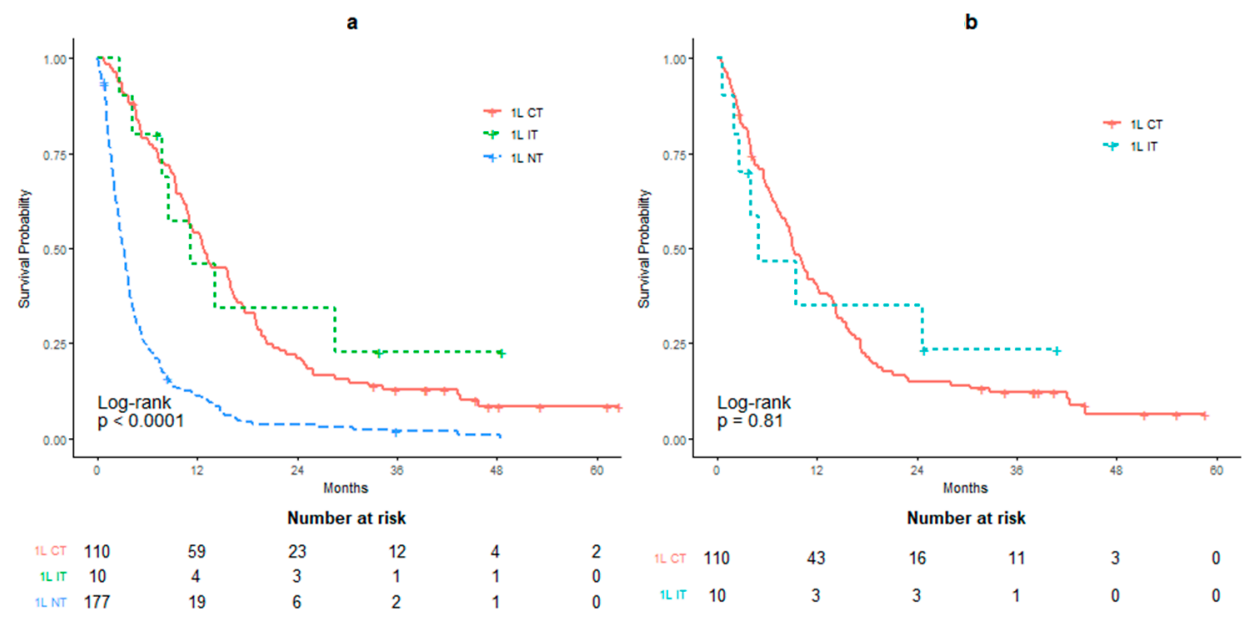

Figure 3. Overall survival in patients receiving first-line palliative therapies. (a) OS calculated from date of metastasis. (b) OS calculated from initiation of first-line therapy. Chemotherapy (1L CT), immunotherapy (1L IT) or no treatment (1L NT).

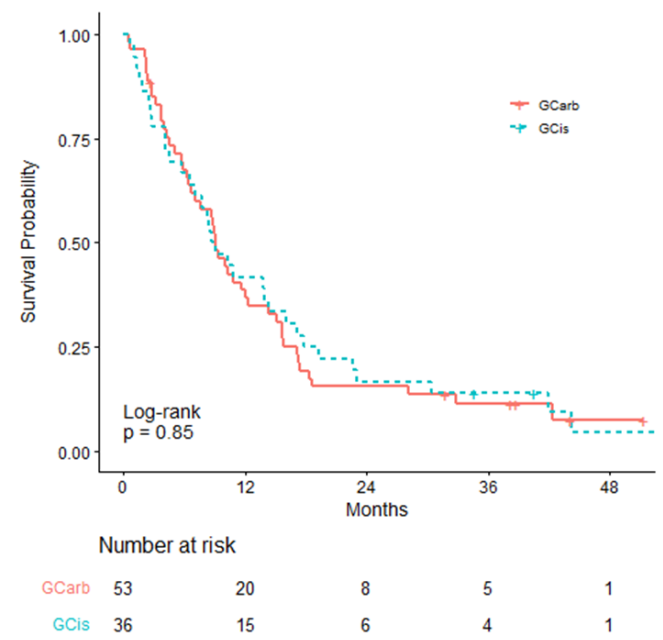

Figure 4. Overall survival in patients receiving first-line palliative chemotherapy, including: gemcitabine and cisplatin (GCis) vs. gemcitabine and carboplatin (GCarb), calculated from initiation of therapy.

Figure 5a and Table A5 compare the OS between 2L therapies versus NT. Calculated from the date that 1L agent was terminated, the mOS for the 2L NT group was 2.92 months, whereas the mOS for the 2L IT and CT groups were 13.43 and 9.34 months, respectively. The difference in mOS between 2L IT and 2L NT was significant (HR: 0.454, $p=0.0047$ ), but 2L CT to 2L NT comparison did not reach statistical significance (HR: 0.639, $p=0.1734$ ). When calculated from the date that $2 \mathrm{~L}$ therapy was initiated, the mOS for the $2 \mathrm{~L}$ IT and CT groups were 6.72 months and 3.78 months, respectively (HR: 0.595; $p=0.15$; Figure $5 \mathrm{~b}$ and Table A6). 

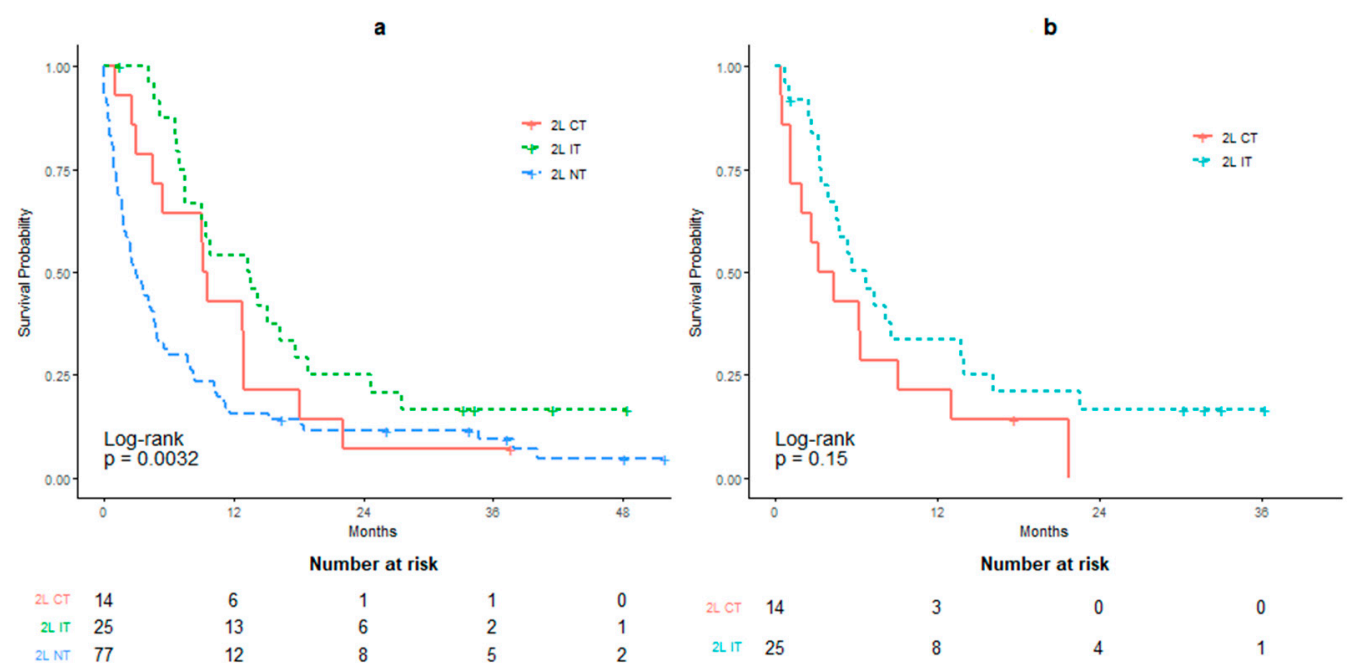

Figure 5. Overall survival (OS) in patients receiving second-line palliative therapies. (a) OS calculated from termination of first-line therapy. (b) OS calculated from initiation of second-line therapy. Therapies include chemotherapy (2L CT), immunotherapy (2L IT) or no treatment (2L NT).

\section{Discussion}

This study outlines observational data on treatment patterns and survival outcomes in patients with metastatic bladder cancer in a multicentre provincial population study. In this study, the majority of patients undergoing first-line PSTs received chemotherapy $(91.7 \%)$ and a smaller portion received immunotherapy $(8.3 \%)$. Real-world data on the use of chemotherapy versus immunotherapy in $1 \mathrm{~L}$ settings are limited. However, 1 study reporting on a cohort of cisplatin-ineligible patients had similar results to our study as patients predominantly received carboplatin-based chemotherapy $(76 \%)$ over immunotherapy (24\%) [10]. In our study, the most commonly used chemotherapy regimens in the $1 \mathrm{~L}$ setting were GCarb and GCis and the preferred $1 \mathrm{~L}$ immunotherapy regimens were atezolizumab and pembrolizumab. In the $2 \mathrm{~L}$ setting, however, the proportion of patients receiving immunotherapy (mainly atezolizumab and pembrolizumab) and chemotherapy (primarily carboplatin-based combination therapies) was $64.1 \%$ and $35.9 \%$, respectively. Of note, in $2 \mathrm{~L}$ settings, atezolizumab was more commonly utilized than pembrolizumab. This is because at the time of our data collection (2014-2016), there was limited evidence supporting the use of either of these agents in $\mathrm{mBC}$ as well as more accessibility to atezolizumab through patient assistance programs offered in British Columbia. Importantly, more than half of the patients with $\mathrm{mBC}$ did not receive any PST and almost two-thirds of individuals did not undergo $2 \mathrm{~L}$ treatment. In comparison, 2 recent retrospective studies looking at uptake of chemotherapy in the US, reported $36 \%$ of patients did not receive $1 \mathrm{~L}$, and $45-66 \%$ did not receive $2 \mathrm{~L}$ systemic therapies $[11,12]$.

Taken from the date of diagnosis of metastasis, in individuals receiving PSTs the mOS was 11.10 and 10.82 months for the IT and CT groups, respectively. Those who received both CT and IT sequentially had a longer mOS of 18.92 months. Conversely, patients not receiving treatment had a mOS of 3.16 months. This difference in survival outcomes was expected as other studies in the literature report an average survival of 9-11 months versus 3-6 months with and without treatment, respectively $[7,10,11]$. This provides support for placing patients on at least one line of PST in the metastatic setting. Furthermore, a real world mOS of over a year and a half is unprecedented and indicates the efficacy of multiple lines of therapy. To our knowledge, this is the first study comparing survival outcomes retrospectively in a patient cohort receiving immunotherapy to patients not receiving any PSTs.

Taken from the date of $1 \mathrm{~L}$ therapy initiation, patients receiving $1 \mathrm{~L} \mathrm{CT}$ had an mOS of 9.13 months, which was slightly shorter than those reported by other retrospective studies (11-12.8 months) $[11,13]$. In contrast, the mOS for 1L IT was approximately half of $1 \mathrm{~L} \mathrm{CT}$ 
at 5.03 months. The difference in survival was not significant possibly due to the small sample size of the IT group. The limited number of patients in the IT group reflects the recent approval of immune checkpoint inhibitors in 2017 by the FDA for use in 1L setting in cisplatin-ineligible patients. The mOS for 1L IT, taken from the date of 1L therapy initiation, was shorter than those reported in other retrospective ( 9 months) and prospective clinical trials (15.9 months) $[10,14]$. This may reflect patient selection of those who received IT as $1 \mathrm{~L}$, including those who have poorer functional status due to multiple comorbidities.

Among 1L platinum-based chemotherapies, GCis is currently the recommended firstline regimen according to guidelines. GCarb is reserved for individuals who are GCis ineligible [6]. There is only one published randomized control trial (RCT) which investigated GCis versus GCarb; however, due to a small sample size, this study did not have sufficient power to reliably compare the efficacy of these treatments head-to-head [15]. In our patient cohort, patients receiving GCis had an mOS of 8.88 months, which is shorter than those reported in both retrospective (13.3 months) and RCTs (12.7-14.0 months) [11,15-17]. Conversely, individuals receiving GCarb had an mOS of 9.13 months, which is consistent with the literature (9.3-10.6 months) $[11,15,18]$. There was no significant difference in the mOS between these two groups despite patients on GCarb likely having a number of comorbidities and/or poor performance status rendering them unfit for GCis therapy. This finding is consistent with the literature in both retrospective and RCT settings [11,15]. Given the comparable efficacies of these two regimens, GCarb could be considered a suitable alternative to GCis for 1L CT.

Calculated from the date that $1 \mathrm{~L}$ agent was terminated, patients in the $2 \mathrm{~L}$ NT group had an mOS of only 2.92 months, which is similar to the results of another retrospective study (2.8 months) and slightly less than that reported by a clinical trial ( 4.3 months) $[19,20]$. Although the mOS of 2L CT (9.34 months) was found to be more than triple that of the 2L NT group, the difference was not statistically significant, potentially due to the small sample size of the CT group. Conversely, the mOS of 2L IT was significantly longer at 13.43 months, demonstrating the importance of immunotherapy access beyond the $1 \mathrm{~L}$ setting. This benefit is also expected to be translated into the $1 \mathrm{~L}$ setting in the future once the maintenance atezolizumab treatment following the 1L CT is approved as an option. In our cohort, none of the patients received maintenance IT.

Calculated from the date of 2L therapy initiation, patients receiving CT had an mOS of 3.78 months, which is shorter than those reported by other retrospective studies (6.83-9.4 months) and clinical trials (6-7 months) [13,20-22]. Similarly, patients on 2L IT had an mOS of 6.72 months, which is shorter than survival outcomes reported by recent RCTs (8.74 months for nivolumab, 10.1 months for pembrolizumab and 11.1 months for atezolizumab) [23-25]. The difference between 2L IT and CT in our study was not found to be significant $(p=0.15)$. The survival benefits of $2 \mathrm{~L} \mathrm{CT}$ remain controversial compared to 2L IT based on recent reports from RCTs. The phase III KEYNOTE-045 study demonstrated a significant benefit in mOS for 2L pembrolizumab versus standard-of-care CT. Conversely, the phase III IMvigor211 study did not report any significant improvements in mOS for $2 \mathrm{~L}$ atezolizumab versus CT [24,25]. To our knowledge, a retrospective study has never been conducted to directly compare 2L IT to either 2L CT or supportive care for patients. Our results can therefore help inform decisions regarding the use of immunotherapy as a $2 \mathrm{~L}$ agent in a real-world setting.

There are several limitations to this study. Firstly, the location(s) of the initial metastatic disease was not collected in this study, and therefore its impact on our survival outcomes is unknown. The discussed immune checkpoint inhibitors were only recently approved by Health Canada in 2016 or later, thus limiting our sample size as many patients did not have access to these treatments during the time that the study was conducted. Furthermore, this study was solely based on a single provincial database in Canada. Therefore, there may be a limited applicability of our findings across different populations. In addition, this study was on patients with bladder cancer and did not include less common sites for urothelial carcinoma such as the ureter or renal pelvis. Lastly, this study did not 
include novel treatment approaches such as combination immunotherapy or targeted therapies with agents such as erdafitinib and enfortumab vedotin. Future studies with larger patient cohorts and longer follow-up times are warranted to rigorously evaluate and shed more light on the efficacy and safety of novel palliative systemic therapies in the real-world setting.

\section{Conclusions}

In summary, we have provided real-world information on treatment patterns and survival outcomes of palliative systemic therapies in treating metastatic bladder cancer. Despite the fact that chemotherapy remains the most widely used treatment modality in first-line setting, our study found immunotherapy to be a comparable alternative. This supports the use of immune checkpoint inhibitors as $1 \mathrm{~L}$ agents in select patients. Within $1 \mathrm{~L}$ chemotherapy agents, guidelines currently recommend GCis over GCarb. Our study, however, showed that GCarb may be as efficacious. Additionally, this study provided further evidence for the effectiveness of immunotherapy in second-line settings.

Author Contributions: Conceptualization, A.B.; S.V.-N. and J.J.K.; methodology, A.B.; S.V.-N. and J.J.K.; validation, J.J.K.; formal analysis, L.H. and S.Z.S.; investigation, A.B. and S.V.-N.; resources, J.J.K.; data curation, A.B. and S.V.-N.; writing — original draft preparation, A.B. and S.V.-N.; writingreview and editing, A.B.; S.V.-N. and J.J.K.; supervision, J.J.K.; project administration, J.J.K.; visualization A.B.; S.V.-N.; L.H. and S.Z.S.; funding acquisition, A.B. and S.V.-N. All authors have read and agreed to the published version of the manuscript.

Funding: This research was in part supported by the UBC Faculty of Medicine (FoM) Summer Research Program and the Louis Lipsey Toohill Scholarship from the UBC FoM.

Institutional Review Board Statement: The study was conducted according to the guidelines of the Declaration of Helsinki and approved by the Institutional Review Board (or Ethics Committee) of UBC BC Cancer (protocol code H18-03314 and 20 November 2018).

Informed Consent Statement: Patient consent was waived due to the nature of the study. This was a retrospective cohort study in which data was collected purely through chart review of the BC Cancer Agency database. Furthermore, there were no patient interactions or interventions performed. It would not have been feasible to consent all the subjects required for this database as some may be lost to follow up or passed away.

Data Availability Statement: Data for this study was collected from the BC Cancer Agency database, which is not publicly available.

Conflicts of Interest: Author Jenny J. Ko declares honorarium from Merck, BMS, Janssen, Astra Zeneca, Bayer, Astellas, Roche, and Takeda as well as research funding from Astra Zeneca and Janssen. No other authors have relevant conflicts of interest. The funders had no role in the design of the study; in the collection, analyses, or interpretation of data; in the writing of the manuscript, or in the decision to publish the results.

\section{Appendix A}

Table A1. Palliative systemic therapy by line.

\begin{tabular}{ccc}
\hline Agents & 1L $(\boldsymbol{N}=\mathbf{2 9 7}), \boldsymbol{n} \mathbf{( \% )}$ & 2L $(\boldsymbol{N}=\mathbf{1 1 6}), \boldsymbol{n} \mathbf{( \% )}$ \\
\hline Chemotherapy & $110(37.0)$ & $14(12.1)$ \\
\hline Gemcitabine + Carboplatin & $53(17.8)$ & $2(5.2)$ \\
\hline Gemcitabine + Cisplatin & $36(12.1)$ & $0(0.0)$ \\
\hline Taxanes alone & $2(0.7)$ & $7(6.0)$ \\
\hline Other $^{\text {a }}$ & $19(6.4)$ & $5(4.3)$ \\
\hline
\end{tabular}


Table A1. Cont.

\begin{tabular}{ccc}
\hline Agents & 1L $(\boldsymbol{N}=\mathbf{2 9 7}), \boldsymbol{n ( \% )}$ & 2L $(\boldsymbol{N}=\mathbf{1 1 6}), \boldsymbol{n} \mathbf{( \% )}$ \\
\hline Immunotherapy & $10(3.4)$ & $25(21.6)$ \\
\hline Atezolizumab & $4(1.3)$ & $16(13.8)$ \\
\hline Pembrolizumab & $4(1.3)$ & $9(7.8)$ \\
\hline Nivolumab & $2(0.7)$ & $0(0.0)$ \\
\hline $\begin{array}{c}\text { No chemotherapy or } \\
\text { immunotherapy }\end{array}$ & $177(59.6)$ & $77(66.4)$ \\
\hline
\end{tabular}

Abbreviations: $1 \mathrm{~L}=$ first-line, $2 \mathrm{~L}=$ second-line. ${ }^{a}$ Other: in $1 \mathrm{~L}$, included cisplatin/etoposide, carboplatin alone, cisplatin alone, gemcitabine alone, carboplatin/etoposide, carboplatin/vinblastine and cyclophosphamide/doxorubicin/vincristine (CAV); in 2L, included pemetrexed, topotecan, carboplatin/irinotecan and carboplatin/5-flurouracil.

Table A2. Median overall survival from time of metastasis for first-line palliative systemic treatments versus no treatment.

\begin{tabular}{|c|c|c|c|}
\hline Overall Survival & $\begin{array}{c}1 \mathrm{~L} \text { IT } \\
N=10\end{array}$ & $\begin{array}{c}1 \mathrm{~L} \mathrm{CT} \\
N=110\end{array}$ & $\begin{array}{c}\text { NT (Reference) } \\
\quad N=177\end{array}$ \\
\hline $\begin{array}{c}\text { mOS } \\
\text { (95\% CI; months) }\end{array}$ & $\begin{array}{c}11.10 \\
(7.79-\mathrm{NA})\end{array}$ & $\begin{array}{c}12.76 \\
(10.95-15.59)\end{array}$ & $\begin{array}{c}3.16 \\
(2.69-3.66)\end{array}$ \\
\hline $\begin{array}{l}\text { Log-rank test } \\
p \text {-value }\end{array}$ & 0.0011 & $<0.0001$ & - \\
\hline $\begin{array}{c}\mathrm{HR} \\
(95 \% \mathrm{CI})\end{array}$ & $\begin{array}{c}0.291 \\
(0.136-0.624)\end{array}$ & $\begin{array}{c}0.310 \\
(0.239-0.402)\end{array}$ & - \\
\hline $\begin{array}{l}\text { Non-proportionality } \\
p \text {-value }\end{array}$ & 0.2 & $<0.0001$ & - \\
\hline $\begin{array}{c}\text { RMST } \\
\text { (95\% CI; months) }\end{array}$ & $\begin{array}{c}19.686 \\
(8.619-30.753)\end{array}$ & $\begin{array}{c}16.909 \\
(14.373-19.445)\end{array}$ & $\begin{array}{c}5.462 \\
(4.333-6.591)\end{array}$ \\
\hline $\begin{array}{l}\text { RMST difference } \\
\text { (95\% CI; months) }\end{array}$ & $\begin{array}{c}14.224 \\
(3.099-25.348)\end{array}$ & $\begin{array}{c}11.446 \\
(8.670-14.222)\end{array}$ & - \\
\hline $\begin{array}{l}\text { RMST difference } \\
p \text {-value }\end{array}$ & 0.012 & $<0.0001$ & - \\
\hline
\end{tabular}

HR: hazard ratio CI: confidence interval; RMST: restricted mean survival time; restricted at 48 months (4 years).

Table A3. Survival outcomes from start date of therapy for first-line palliative immunotherapy and chemotherapy.

\begin{tabular}{ccc}
\hline Overall Survival & 1L IT & 1L CT (Reference) \\
& $N=\mathbf{1 0}$ & $\mathbf{N}=\mathbf{1 1 0}$ \\
\hline mOS & 5.03 & 9.13 \\
$(95 \%$ CI; months $)$ & $(2.69-\mathrm{NA})$ & $(7.72-12.10)$ \\
\hline HR & 0.911 & - \\
$(95 \%$ CI $)$ & $(0.422-1.967)$ & - \\
\hline Log-rank test & 0.81 & \\
$p$-value & &
\end{tabular}

1L CT: first-line chemotherapy; 1L IT: first-line immunotherapy; NT: no treatment. mOS: median overall survival. HR: hazard ratio. CI: confidence interval. 
Table A4. Survival outcomes in patients receiving first line palliative chemotherapy including: gemcitabine and cisplatin (GCis) vs. gemcitabine and carboplatin (GCarb).

\begin{tabular}{ccc}
\hline Overall Survival & $\begin{array}{c}\text { GCarb } \\
N=53\end{array}$ & $\begin{array}{c}\text { GCis (Reference) } \\
N=36\end{array}$ \\
\hline mOS & 9.13 & 8.88 \\
$(95 \%$ CI; months $)$ & $(6.69-14.30)$ & $(6.53-16.10)$ \\
\hline HR & 1.044 & - \\
$(95 \% \mathrm{CI})$ & $(0.668-1.633)$ & - \\
\hline $\begin{array}{c}\text { Log-rank test } \\
p \text {-value }\end{array}$ & 0.85 & \\
\hline $\begin{array}{l}\text { GCarb: Gemcitabine/carboplatin; GCis: Gemcitabine/cisplatin. mOS: median overall survival. HR: hazard ratio. } \\
\text { CI: confidence interval. }\end{array}$
\end{tabular}

Table A5. Median overall survival from termination of first-line therapy for second-line palliative systemic treatments versus no treatment.

\begin{tabular}{|c|c|c|c|}
\hline Overall Survival & $\begin{array}{c}2 \mathrm{~L} \mathrm{IT} \\
N=25\end{array}$ & $\begin{array}{l}2 \mathrm{~L} \mathrm{CT} \\
N=14\end{array}$ & $\begin{array}{c}\text { 2L NT (Reference) } \\
\qquad N=77\end{array}$ \\
\hline $\begin{array}{c}\text { mOS } \\
\text { (95\% CI; months) }\end{array}$ & $\begin{array}{c}13.43 \\
(9.10-18.82)\end{array}$ & $\begin{array}{c}9.34 \\
(5.46-22.10)\end{array}$ & $\begin{array}{c}2.92 \\
(1.85-4.82)\end{array}$ \\
\hline $\begin{array}{l}\text { Log-rank test } \\
p \text {-value }\end{array}$ & 0.0047 & 0.1734 & - \\
\hline $\begin{array}{c}\mathrm{HR} \\
(95 \% \mathrm{CI})\end{array}$ & $\begin{array}{c}0.454 \\
(0.275-0.749)\end{array}$ & $\begin{array}{c}0.639 \\
(0.352-1.160)\end{array}$ & - \\
\hline $\begin{array}{l}\text { Non-proportionality } \\
p \text {-value }\end{array}$ & 0.0002 & 0.0075 & - \\
\hline $\begin{array}{c}\text { RMST } \\
\text { (95\% CI; months) }\end{array}$ & $\begin{array}{c}15.95 \\
(11.67-20.24)\end{array}$ & $\begin{array}{c}11.36 \\
(6.66-17.87)\end{array}$ & $\begin{array}{c}7.65 \\
(5.20-10.09)\end{array}$ \\
\hline $\begin{array}{l}\text { RMST difference } \\
\text { (95\% CI; months) }\end{array}$ & $\begin{array}{c}8.31 \\
(3.38-13.24)\end{array}$ & $\begin{array}{c}3.71 \\
(-1.59-9.00)\end{array}$ & - \\
\hline $\begin{array}{c}\text { RMST difference } \\
p \text {-value }\end{array}$ & 0.001 & 0.170 & - \\
\hline
\end{tabular}

Table A6. Survival outcomes from start date of therapy for second-line palliative immunotherapy and chemotherapy.

\begin{tabular}{|c|c|c|}
\hline Overall Survival & $\begin{array}{c}2 \mathrm{~L} \text { IT } \\
N=25\end{array}$ & $\begin{array}{c}\text { 2L CT (Reference) } \\
\qquad N=14\end{array}$ \\
\hline $\begin{array}{c}\text { mOS } \\
\text { (95\% CI; months) }\end{array}$ & $\begin{array}{c}6.72 \\
(4.59-16.10)\end{array}$ & $\begin{array}{c}3.78 \\
(1.99-\mathrm{NA})\end{array}$ \\
\hline $\begin{array}{c}\text { HR } \\
(95 \% \mathrm{CI})\end{array}$ & $\begin{array}{c}0.595 \\
(0.293-1.209)\end{array}$ & - \\
\hline $\begin{array}{c}\text { Log-rank test } \\
p \text {-value }\end{array}$ & 0.15 & - \\
\hline
\end{tabular}

2L CT: second-line chemotherapy; 2L IT: second-line immunotherapy. mOS: median overall survival. HR: hazard ratio. CI: confidence interval. 


\section{References}

1. Torre, L.A.; Bray, F.; Siegel, R.L.; Ferlay, J.; Lortet-Tieulent, J.; Jemal, A. Global cancer statistics, 2012. CA Cancer J. Clin. 2015, 65, 87-108. [CrossRef]

2. Key Statistics for Bladder Cancer. (8 January 2020). Available online: https:/ / www.cancer.org/cancer/bladder-cancer/about/ key-statistics.html (accessed on 7 September 2020).

3. Malkowicz, S.B.; van Poppel, H.; Mickisch, G.; Pansadoro, V.; Thüroff, J.; Soloway, M.S.; Chang, S.; Benson, M.; Fukui, I. Muscle-invasive urothelial carcinoma of the bladder. Urology 2007, 69 (Suppl. 1), 3-16. [CrossRef]

4. National Institutes of Health National Cancer Institute. Surveillance, Epidemiology, and End Results Program. SEER Cancer Stat Facts: Bladder Cancer. Available online: https://seer.cancer.gov/statfacts/html/urinb.html (accessed on 11 August 2017).

5. Chalasani, V.; Chin, J.L.; Izawa, J.I. Histologic variants of urothelial bladder cancer and nonurothelial histology in bladder cancer. Can. Urol. Assoc. J. 2009, 3 (Suppl. 4), S193-S198. [CrossRef] [PubMed]

6. Witjes, J.A.; Compérat, E.; Cowan, N.C.; De Santis, M.; Gakis, G.; Lebret, T.; Ribal, M.J.; Van der Heijden, A.G.; Sherif, A. EAU guidelines on muscle-invasive and metastatic bladder cancer: Summary of the 2013 guidelines. Eur. Urol. 2014, 65, 778-792. [CrossRef] [PubMed]

7. Galsky, M.D.; Hahn, N.M.; Bellmunt, J.; Rosenberg, J.; Sonpavde, G.; Hutson, T.; Oh, W.K.; Dreicer, R.; Vogelzang, N.; Sternberg, C.N.; et al. Treatment of patients with metastatic urothelial cancer "Unfit" for cisplatin-based chemotherapy. J. Clin. Oncol. 2011, 29, 2432-2438. [CrossRef] [PubMed]

8. Powles, T.; Grivas, P.; Aragon-Ching, J.B.; Faroun, Y.; Kessler, E.R.; Tomita, Y.; Chakrabarti, D.; Laliberte, R.J.; Shnaidman, M.; Petrylak, D. A multicentre, international, randomised, open-label phase 3 trial of avelumab + best supportive care (BSC) vs. BSC alone as maintenance therapy after first-line platinum-based chemotherapy in patients with advanced urothelial cancer. J. Clin. Oncol. 2016, 27, vi292. [CrossRef]

9. Amin, M.B.; Greene, L.F.; Edge, S.B.; Compton, C.C.; Gershenwald, E.J.; Brookland, R.K.; Meyer, L.; Gress, D.M.; Byrd, D.R.; Winchester, D.P. The Eighth Edition AJCC Cancer Staging Manual: Continuing to build a bridge from a population-based to a more "personalized" approach to cancer staging. CA Cancer J. Clin. 2017, 67, 93-99. [CrossRef]

10. Feld, E.; Harton, J.; Meropol, N.J.; Adamson, B.J.; Cohen, A.; Parikh, R.B.; Galsky, M.D.; Narayan, V.; Christodouleas, J.; Vaghn, D.J.; et al. Effectiveness of first-line immune checkpoint blockade versus carboplatin-based chemotherapy for metastatic urothelial cancer. Eur. Urol. 2019, 76, 524-532. [CrossRef]

11. Fisher, M.D.; Shenolikar, R.; Miller, P.J.; Fenton, M.; Walker, M.S. Treatment patterns and outcomes in stage IV bladder cancer in a community oncology setting: 2008-2015. Clin. Genitourin. Cancer 2018, 16, e1171-e1179. [CrossRef]

12. Flannery, K.; Black-Shinn, J.; Boyd, M.; Robert, N.; Kamat, A. Second-line treatment patterns and outcomes of metastatic bladder cancer patients in clinical practice. Ann. Oncol. 2017, 28 (Suppl. 5), v295-v329. [CrossRef]

13. Flannery, K.; Boyd, M.; Black-Shinn, J.; Robert, N.; Kamat, A.M. Outcomes in patients with metastatic bladder cancer in the USA: A retrospective electronic medical record study. Future Oncol. 2019, 15, 1323-1334. [CrossRef] [PubMed]

14. Balar, A.V.; Galsky, M.D.; Rosenberg, J.E.; Powles, T.; Petrylak, D.P.; Bellmunt, J.; Loriot, Y.; Necchi, A.; Hoffman-Censits, J.; Perez-Gracia, J.L.; et al. Atezolizumab as first-line treatment in cisplatin-ineligible patients with locally advanced and metastatic urothelial carcinoma: A single-arm, multicentre, phase 2 trial. Lancet 2017, 389, 67-76. [CrossRef]

15. Dogliotti, L.; Cartenì, G.; Siena, S.; Bertetto, O.; Martoni, A.; Bono, A.; Amadori, D.; Onat, H.; Marini, L. Gemcitabine plus cisplatin versus gemcitabine plus carboplatin as first-line chemotherapy in advanced transitional cell carcinoma of the urothelium: Results of a randomized phase 2 trial. Eur. Urol. 2007, 52, 134-141. [CrossRef] [PubMed]

16. Bellmunt, J.; von der Maase, H.; Mead, G.M.; Skoneczna, I.; De Santis, M.; Daugaard, G.; Boehle, A.; Chevreau, C.; Paz-Ares, L.; Laufman, L.R.; et al. Randomized phase III study comparing paclitaxel/cisplatin/gemcitabine and gemcitabine/cisplatin in patients with locally advanced or metastatic urothelial cancer without prior systemic therapy: EORTC Intergroup Study $30987 . J$. Clin. Oncol. 2012, 30, 1107-1113. [CrossRef] [PubMed]

17. Von der Maase, H.; Sengelov, L.; Roberts, J.T.; Ricci, S.; Dogliotti, L.; Oliver, T.; Moore, M.J.; Zimmermann, A.; Arning, M. Longterm survival results of a randomized trial comparing gemcitabine plus cisplatin, with methotrexate, vinblastine, doxorubicin, plus cisplatin in patients with bladder cancer. J. Clin. Oncol. 2005, 23, 4602-4608. [CrossRef]

18. De Santis, M.; Bellmunt, J.; Mead, G.; Kerst, J.M.; Leahy, M.; Maroto, P.; Gil, T.; Marreaud, S.; Daugaard, G.; Skoneczna, I.; et al. Randomized phase II/III trial assessing gemcitabine/carboplatin and methotrexate/carboplatin/vinblastine in patients with advanced urothelial cancer who are unfit for cisplatin-based chemotherapy: EORTC study 30986. J. Clin. Oncol. 2012, 30, 191-199. [CrossRef] [PubMed]

19. Bellmunt, J.; Théodore, C.; Demkov, T.; Komyakov, B.; Sengelov, L.; Daugaard, G.; Caty, A.; Carles, J.; Jagiello-Gruszfeld, A.; Karyakin, O.; et al. Phase III trial of vinflunine plus best supportive care compared with best supportive care alone after a platinum-containing regimen in patients with advanced transitional cell carcinoma of the urothelial tract. J. Clin. Oncol. 2009, 27, 4454-4461. [CrossRef]

20. Tsang, E.S.; Forbes, C.; Chi, K.N.; Eigl, B.J.; Parimi, S. Second-line systemic therapies for metastatic urothelial carcinoma: A population-based cohort analysis. Curr. Oncol. 2019, 26, e260-e265. [CrossRef]

21. Furubayashi, N.; Negishi, T.; Yamashita, T.; Kusano, S.; Taguchi, K.; Shimokawa, M.; Nakamura, M. The combination of paclitaxel and carboplatin as second-line chemotherapy can be a preferred regimen for patients with urothelial carcinoma after the failure of gemcitabine and cisplatin chemotherapy. Mol. Clin. Oncol. 2017, 7, 1112-1118. [CrossRef] 
22. Choueiri, T.K.; Ross, R.W.; Jacobus, S.; Vaishampayan, U.; Yu, E.Y.; Quinn, D.I.; Hahn, N.M.; Hutson, T.E.; Sponpavde, G.; Morrissey, S.C.; et al. Double-blind, randomized trial of docetaxel plus vandetanib versus docetaxel plus placebo in platinumpretreated metastatic urothelial cancer. J. Clin. Oncol. 2012, 30, 507-512. [CrossRef]

23. Sharma, P.; Retz, M.; Siefker-Radtke, A.; Baron, A.; Necchi, A.; Bedke, J.; Galsky, M.D. Nivolumab in metastatic urothelial carcinoma after platinum therapy (CheckMate 275): A multicentre, single-arm, phase 2 trial. Lancet Oncol. 2017, 18, 312-322. [CrossRef]

24. Fradet, Y.; Bellmunt, J.; Vaughn, D.J.; Lee, J.L.; Fong, L.; Vogelzang, N.J.; Climent, M.A.; Petrylak, D.P.; Choueiri, T.K.; Necchi, A.; et al. Randomized phase III KEYNOTE-045 trial of pembrolizumab versus paclitaxel, docetaxel, or vinflunine in recurrent advanced urothelial cancer: Results of $>2$ years of follow-up. Ann. Oncol. 2019, 30, 970-976. [CrossRef]

25. Powles, T.; Durán, I.; Van der Heijden, M.S.; Loriot, Y.; Vogelzang, N.J.; De Giorgi, U.; Oudard, S.; Retz, M.M.; Castellano, D.; Bamias, A.; et al. Atezolizumab versus chemotherapy in patients with platinum-treated locally advanced or metastatic urothelial carcinoma (IMvigor211): A multicentre, open-label, phase 3 randomised controlled trial. Lancet 2018, 391, 748-757. [CrossRef] 